\title{
Postprandial endothelial dysfunction in subjects with new-onset type 2 diabetes: an acarbose and nateglinide comparative study
}

\author{
Toru Kato' 1 , Teruo Inoue*2 and Koichi Node ${ }^{3}$
}

\begin{abstract}
Background: Postprandial hyperglycemia is believed to affect vascular endothelial function. The aim of our study was to compare the effects of acarbose and nateglinide on postprandial endothelial dysfunction.

Methods: We recruited a total of 30 patients with newly diagnosed type 2 diabetes ( 19 men and 11 women, age 67.8 \pm 7.3 years). Patients were randomly assigned to 3 groups receiving either $300 \mathrm{mg} /$ day acarbose, $270 \mathrm{mg} /$ day nateglinide, or no medication. A cookie test (consisting of $75 \mathrm{~g}$ carbohydrate, $25 \mathrm{~g}$ butter fat, and $7 \mathrm{~g}$ protein for a total of $553 \mathrm{kcal}$ ) was performed as dietary tolerance testing. During the cookie test, glucose and insulin levels were determined at 0, 30, 60, and 120 min after load. In addition, endothelial function was assessed by \% flow-mediated dilation (FMD) of the brachial artery at 0 and 120 min after cookie load.
\end{abstract}

Results: Postprandial glucose and insulin levels were similar in the 3 groups. Postprandial endothelial dysfunction was similar in the 3 groups before treatment. After 12 weeks of intervention, postprandial FMD was significantly improved in the acarbose group compared with the control group ( $6.8 \pm 1.3 \%$ vs $5.2 \pm 1.1 \%, p=0.0022)$. Area under the curve (AUC) for insulin response was significantly increased in the nateglinide and control groups; however, no significant change was observed in the acarbose group.

Conclusions: Our results suggest that acarbose improves postprandial endothelial function by improvement of postprandial hyperglycemia, independent of postprandial hyperinsulinemia. Acarbose may thus have more beneficial effects on postprandial endothelial function in patients with type 2 diabetes than nateglinide.

\section{Introduction}

Epidemiological studies have revealed that postprandial hyperglycemia is a more powerful predictor of future cardiovascular events than fasting hyperglycemia $[1,2]$. Endothelial dysfunction is not only an early marker of atherosclerosis but is also strongly associated with risk of future cardiovascular events [3]. Endothelial dysfunction is associated with cardiovascular risk factors such as smoking [4], dyslipidemia [5,6], hypertension $[7,8]$, obesity [9], type 2 diabetes [10], and postprandial hyperglycemia [11]. Postprandial endothelial dysfunction, postprandial hyperglycemia and cardiovascular events are all strongly associated with one another $[12,13]$.

* Correspondence: inouet@dokkyomed.ac.jp

2 Department of Cardiovascular Medicine, Dokkyo Medical University, Mibu, Tochigi, Japan

Full list of author information is available at the end of the article
Since the postprandial state occurs during most of the daytime, interventions that aim to reduce postprandial endothelial dysfunction are essential for the prevention of cardiovascular events. Currently, there is no gold standard for treatment of postprandial endothelial dysfunction. However, several pharmacological therapeutic approaches have been suggested. Potential agents to target postprandial hyperglycemia in patients with type 2 diabetes include $\alpha$-glucosidase inhibitors and glinide drugs. Acarbose, an $\alpha$-glucosidase inhibitor, reduces or delays carbohydrate digestion by competitive and dosedependent inhibition of $\alpha$-glucosidase enzymes located in the brush border of the small intestine. The $\alpha$-glucosidase enzymes metabolize non-absorbable oligosaccharides into absorbable monosaccharides. Thus, acarbose significantly reduces the postprandial rise in glucose without increasing circulating insulin levels. Recent clinical trials 
have shown that acarbose treatment can prevent cardiovascular complications not only in patients with type 2 diabetes but also in those with impaired glucose tolerance $[14,15]$. Thus, acarbose may be an effective therapeutic modality in patients with postprandial hyperglycemia.

In contrast, the D-phenylalanine derivative nateglinide is an insulinotropic agent with rapid effects and a short duration of action which acts as an insulin secretagogue in the treatment of type 2 diabetes, and which is reported to lower the 24-h glucose profile without increasing total insulin secretion $[16,17]$.

Although the effects of solo administration of acarbose or nateglinide on the improvement of postpandial endothelial function have been assessed [18-20], there are no comparative studies looking at both agents. In this open-label prospective study, we compared the effects of acarbose and nateglinide on postprandial endothelial function in newly diagnosed type 2 diabetes.

\section{Methods Study design}

We recruited a total of 30 patients with type 2 diabetes (19 men and 11 women, age $67.8 \pm 7.3$ years, HbA1c $6.0 \pm$ $0.5 \%)$, who were diagnosed according to the WHO criteria [21]. Subjects were advised to consume their normal diet during the entire period of the study. Smokers, subjects who had any history of cardiovascular disease, and subjects taking lipid lowering agents or supplemental vitamins were excluded. All of the study subjects were randomly assigned to receive one of the following treatments for 12 weeks: $300 \mathrm{mg} / \mathrm{d}$ acarbose $(\mathrm{n}=10), 270 \mathrm{mg} /$ $\mathrm{d}$ nateglinide $(\mathrm{n}=10)$ or no medication $(\mathrm{n}=10)$ as a control group. At the initiation of treatment and at the end of 12 weeks of treatment, cookie test was performed as a dietary tolerance test. Written informed consent was obtained from all subjects, with local ethics committee approval.

\section{Cookie test}

The cookie test was performed after overnight fasting, using previously described methods [22], at baseline before treatment and 12 weeks after treatment. Subjects were instructed to refrain from smoking and drinking coffee or alcoholic beverages beginning the night before the study. The cookie consisted of 75 g carbohydrate $(85 \%$ flour starch, 15\% maltose), $25 \mathrm{~g}$ butter and $7 \mathrm{~g}$ protein for a total of $553 \mathrm{kcal}$. (ABILIT Corp, Osaka, Japan). Subjects were encouraged to ingest the cookie with water within $15 \mathrm{~min}$. Time measurement was started at the time when half of the cookie had been ingested. Blood samples were obtained during the fasting state before cookie ingestion, and at $30 \mathrm{~min}, 60 \mathrm{~min}$ and $120 \mathrm{~min}$ after the cookie load. Plasma glucose and insulin levels were determined at each time point. Vascular endothelial function was assessed in the fasting state before cookie ingestion and $120 \mathrm{~min}$ after the cookie load as the postprandial state.

\section{Biochemical measurement}

Plasma glucose levels were measured using the glucoseoxidase method, and plasma insulin levels were measured by immunoassay). Glycohemoglobin (Hb) A1c was measured by high-performance liquid chromatography. From the fasting glucose and insulin levels, insulin resistance was assessed using homeostasis model assessment (HOMA-IR) according to the following formula: fasting plasma glucose $(\mathrm{mg} / \mathrm{dl}) \times$ fasting plasma insulin $(\mu \mathrm{U} / \mathrm{ml}) /$ 405 [23].

Using the fasting blood samples taken before cookie ingestion, the levels of total cholesterol (TC) and triglycerides (TG) were measured enzymatically. High-density lipoprotein cholesterol (HDL-C) was estimated after precipitation of apolipoprotein B with phosphotungstate/ magnesium. The low-density lipoprotein cholesterol (LDL-C) level was calculated according to the Friedewald formula [24].

\section{Assessment of vascular endothelial function}

Vascular endothelial function was assessed by measuring flow-mediated dilation (FMD) of the brachial artery using established and validated methods [25,26]. A high-resolution ultrasound system was equipped with vascular software for 2-dimensional imaging with a pulse Doppler flow velocimeter, and a linear array transducer probe with a frequency of $7.5 \mathrm{MHz}$ was used (SSA-550A, Toshiba, Japan). The study was performed in the morning under fasting conditions, after resting quietly for at least 10 minutes in a light- and temperature-controlled room. After baseline measurements of the brachial artery diameter, a blood pressure cuff was inflated to $200 \mathrm{~mm} \mathrm{Hg}$ over the proximal portion of the right forearm for $5 \mathrm{~min}$ utes. FMD was determined 1 minute after release of the cuff. The FMD is expressed as the maximum change in diameter after cuff release normalized to the baseline diameter (\% of baseline diameter). Response to $150 \mu \mathrm{g}$ of nitroglycerine was used for assessment of endotheliumindependent nitroglycerin-mediated dilation (\%NMD) of the brachial artery.

\section{Statistical Analysis}

Results are expressed as means \pm SD. The KolmogorovSmirnov algorithm was used to determine whether each variable had a normal distribution. Comparisons of baseline data among the three groups were performed with one-way analysis of variance (ANOVA) followed by a post-hoc Fisher's PLSD test. The paired Student's $t$ test was used for comparison of the various parameters before and after treatment. Changes in measured variables during the tests were assessed by 2-way ANOVA with repeated measures. If differences reached statistical 
significance, post hoc analysis with a 2-tailed paired $t$ test was used to assess differences at individual time points in the study, with the Bonferroni correction used for multiple comparisons. The area under the curve (AUC) was calculated by the trapezoidal method. Statistical significance was defined as $P<0.05$. All statistical analyses were performed using SPSS 11.0.1J for Windows (SPSS Inc.)

\section{Results}

Characteristics of study subjects before and after treatment Baseline characteristics before treatment including age, sex, body mass index (BMI), lipid parameters, HbA1c, glucose, insulin, HOMA-IR, systolic and diastolic blood pressure, and heart rate were similar among the 3 groups. Characteristics of the study subjects after 12 weeks of treatment were also similar among the 3 groups (Table 1).

\section{Glucose and insulin levels during cookie test}

Blood pressure and heart rate did not change during the cookie test (from baseline values to $120 \mathrm{~min}$ after cookie load) at baseline before treatment (143.5 \pm 28.5/89.1 \pm 19.2 to $142.5 \pm 25.4 / 86.9 \pm 19.6 \mathrm{mmHg}, 68.8 \pm 9.8$ to 68.1 $\pm 9.4 / \mathrm{min}$ in the control group, $141.1 \pm 26.1 / 88.1 \pm 23.1$ to $142.6 \pm 26.4 / 86.5 \pm 26.5 \mathrm{mmHg}, 69.2 \pm 11.1$ to $67.9 \pm$ 11.0 in the acarbose group and $141.3 \pm 28.5 / 88.3 \pm 11.9$ to $142.9 \pm 24.2 / 89.4 \pm 21.5 \mathrm{mmHg}, 68.2 \pm 8.9$ to $67.1 \pm 9.6 /$ min in the nateglinide group) and after 12 weeks of treatment $(145.5 \pm 38.2 / 89.3 \pm 11.9$ to $145.8 \pm 34.2 / 87.5 \pm 16.1$ $\mathrm{mmHg}, 68.8 \pm 8.9$ to $68.1 \pm 9.4 / \mathrm{min}$ in the control group, $142.6 \pm 19.1 / 83.1 \pm 38.9$ to $142.9 \pm 28.9 / 84.6 \pm 32.6$ $\mathrm{mmHg}, 62.9 \pm 11.2$ to $63.9 \pm 11.1$ in the acarbose group and $143.8 \pm 23.5 / 68.9 \pm 8.2$ to $142.2 \pm 22.9 / 89.2 \pm 26.7$ $\mathrm{mmHg}, 68.9 \pm 8.2$ to $67.1 \pm 9.9 / \mathrm{min}$ in the nateglinide group).

Plasma glucose levels were significantly decreased at 30 min during the cookie test after 12 weeks of acarbose treatment (from $165.9 \pm 29.1 \mathrm{mg} / \mathrm{dl}$ to $137.0 \pm 26.2, \mathrm{p}=$ 0.031). Plasma insulin levels were significantly increased at 30 and $60 \mathrm{~min}$ after 12 weeks of nateglinide treatment (from $17.8 \pm 12.2$ to $40.5 \pm 9.4 \mathrm{uU} / \mathrm{ml}, \mathrm{p}=0.00019$, and from $28.6 \pm 16.7$ to $47.6 \pm 14.6 \mathrm{uU} / \mathrm{ml}, \mathrm{p}=0.0078$, respectively) (Fig. 1). The AUCs for glucose and insulin levels during the cookie test were calculated before and after treatment. Before treatment, the AUC for glucose levels was similar among the 3 groups $(2041.8 \pm 236.7 \mathrm{mg} / \mathrm{dl} \times \mathrm{h}$ in the control group, $2234.3 \pm 326.7 \mathrm{mg} / \mathrm{dl} \times \mathrm{h}$ in the acarbose group, $2209.0 \pm 306.8 \mathrm{mg} / \mathrm{dl} \times \mathrm{h}$ in the nateglinide group). After 12 weeks of treatment, the AUC for glucose levels was significantly decreased in all 3 groups $(\mathrm{p}<$ 0.00001 in every group) without any intergroup difference (to $1420.4 \pm 127.8 \mathrm{mg} / \mathrm{dl} \times \mathrm{h}$ in the control group, to $1354.1 \pm 293.2 \mathrm{mg} / \mathrm{dl} \times \mathrm{h}$ in the acarbose group, and to $1389.9 \pm 212.2 \mathrm{mg} / \mathrm{dl} \times \mathrm{h}$ in the nateglinide group). Before treatment, the AUC for insulin levels before treatment was also similar among the 3 groups $(421.9 \pm 185.3 \mathrm{uU} /$ $\mathrm{ml} \times \mathrm{h}$ in the control group, $464.4 \pm 164.8 \mathrm{uU} / \mathrm{ml} \times \mathrm{h}$ in the acarbose group, and $315.8 \pm 153.5 \mathrm{uU} / \mathrm{ml} \times \mathrm{h}$ in the nateglinide group). After 12 weeks of treatment, the AUC for insulin levels was significantly increased in the control and nateglinide groups (to $678.9 \pm 196.3 \mathrm{uU} / \mathrm{ml} \times \mathrm{h}, \mathrm{p}=$ 0.007 , and to $915.1 \pm 298.8 \mathrm{uU} / \mathrm{ml} \times \mathrm{h}, \mathrm{p}<0.00001$, respectively). However, it did not change in the acarbose group $(636.7 \pm 275.8 \mathrm{uU} / \mathrm{ml} \times \mathrm{h}, \mathrm{p}=0.17)$.

\section{Effects of acarbose or nateglinide on postprandial endothelial function}

At baseline before treatment, the baseline brachial artery diameter was similar among the control, acarbose and nateglinide groups $(4.1 \pm 0.3,4.1 \pm 0.3$ and $4.0 \pm 0.3 \mathrm{~mm}$, respectively). Fasting FMD was also similar among the 3 groups. Postprandial FMD (120 min after cookie load) was significantly lower than fasting FMD in each group $(4.2 \pm 1.3$ vs. $9.6 \pm 2.7$ in the control group, $4.5 \pm 1.3$ vs. $8.9 \pm 2.2$ in the acarbose group, and $4.4 \pm 2.2$ vs. $8.4 \pm$ $3.1 \%$ in the nateglinide group, $\mathrm{p}<0.001$ for each).

After 12 weeks of treatment, fasting FMD did not change significantly in any of the 3 groups (to $10.2 \pm 2.1$ in the control group, $8.3 \pm 3.2$ in the acarbose group and $8.6 \pm 3.2 \%$ in the nateglinide group), compared to the baseline before treatment. Postprandial FMD was lower in each group after 12 weeks of treatment $(5.2 \pm 1.0$ in the control group, $\mathrm{p}<0.001,6.8 \pm 1.3$ in the acarbose group, $\mathrm{p}<0.05$ and $5.6 \pm 1.9 \%$ in the nateglinide group $\mathrm{p}=0.05$ ) than fasting FMD. Postprandial FMD in the acarbose group was significantly higher $(\mathrm{p}<0.05)$ than that of the control group (Fig. 2) after 12 weeks of treatment. The percent postprandial decrease in FMD [(postprandial FMD-fasting FMD) $\times$ 100/fasting FMD] was significantly suppressed in the acarbose group after 12 weeks of treatment compared to the control group $(-1.5 \pm 0.95$ vs. -5.0 $\pm 2.4 \%, \mathrm{p}<0.001)$ or to the nateglinide group $(-3.2 \pm 1.6 \%$, $\mathrm{p}<0.05)$. The postprandial decrease in FMD in the nateglinide group was also suppressed, compared to that in the control group ( $<<0.01$ ) (Fig. 3).

Postprandial \%NMD was similar to fasting \%NMD in each group. Postprandial and fasting \%NMD were similar among the 3 treatment groups at baseline before treatment and also after 12 weeks of treatment.

\section{Discussion}

Our study has demonstrated that 12 weeks of treatment with acarbose or nateglinide improved postprandial endothelial dysfunction in newly diagnosed type 2 diabetic subjects and that acarbose was more effective than nateglinide. To the best of our knowledge, this is the first study to directly compare the effects of the $\alpha$-glucosidase inhibitor acarbose and the glinide drug nateglinide on postprandial endothelial function. 
Table 1: Characteristics of study subjects before and after treatment

\begin{tabular}{|c|c|c|c|c|c|c|}
\hline & \multicolumn{2}{|c|}{ Control $(n=10)$} & \multicolumn{2}{|c|}{ Acarbose $(n=10)$} & \multicolumn{2}{|c|}{ Nateglinide $(n=10)$} \\
\hline & Baseline & 12 weeks & Baseline & 12 weeks & Baseline & 12 weeks \\
\hline Age (years) & $68.0 \pm 7.7$ & & $67.6 \pm 6.2$ & & $67.8+/-8.6$ & \\
\hline $\begin{array}{l}\text { Male gender } \\
\text { (\%) }\end{array}$ & $5(50)$ & & $7(70)$ & & $7(70)$ & \\
\hline BMI $\left(\mathrm{kg} / \mathrm{m}^{2}\right)$ & $26.8 \pm 3.2$ & $26.1 \pm 3.4$ & $25.8 \pm 2.5$ & $25.3 \pm 7.4$ & $25.8 \pm 3.3$ & $25.5 \pm 2.9$ \\
\hline $\begin{array}{l}\text { Total } \\
\text { cholesterol } \\
(\mathrm{mg} / \mathrm{dl})\end{array}$ & $213.2 \pm 15.9$ & $210.2 \pm 23.2$ & $201.8 \pm 25.4$ & $205.7 \pm 38.1$ & $206.0 \pm 25.4$ & $211.1 \pm 29.6$ \\
\hline $\begin{array}{l}\text { Triglyceride } \\
(\mathrm{mg} / \mathrm{dl})\end{array}$ & $132.4 \pm 13.1$ & $127.7 \pm 17.1$ & $116.1 \pm 20.8$ & $125.5 \pm 34.7$ & $121.7 \pm 19.3$ & $121.6 \pm 22.3$ \\
\hline $\begin{array}{l}\text { HDL } \\
\text { cholesterol } \\
(\mathrm{mg} / \mathrm{dl})\end{array}$ & $53.8 \pm 11.0$ & $53.7 \pm 9.5$ & $56.2 \pm 11.0$ & $52.7 \pm 14.4$ & $54.4 \pm 12.5$ & $57.4 \pm 13.2$ \\
\hline $\begin{array}{l}\text { LDL } \\
\text { cholesterol } \\
\text { (mg/dl) }\end{array}$ & $135.0 \pm 48.8$ & $143.9 \pm 52.7$ & $141.6 \pm 69.3$ & $137.4 \pm 77.3$ & $149.4 \pm 76.0$ & $121.6 \pm 22.3$ \\
\hline HbA1c (\%) & $5.8 \pm 0.6$ & $5.6 \pm 0.5$ & $6.0 \pm 0.3$ & $5.9 \pm 0.4$ & $6.1 \pm 0.6$ & $5.8 \pm 0.4$ \\
\hline $\begin{array}{l}\text { Fasting } \\
\text { glucose } \\
\text { (mg/dl) }\end{array}$ & $110.7 \pm 15.0$ & $109.3 \pm 12.0$ & $109.6 \pm 17.5$ & $108.8 \pm 15.7$ & $119.6 \pm 17.5$ & $110.4 \pm 11.1$ \\
\hline $\begin{array}{l}\text { Fasting insulin } \\
(\mu \mathrm{U} / \mathrm{ml})\end{array}$ & $7.5 \pm 2.9$ & $7.2 \pm 2.8$ & $9.6 \pm 5.6$ & $10.6 \pm 6.8$ & $6.6 \pm 4.1$ & $6.5 \pm 2.7$ \\
\hline HOMA-IR & $2.0 \pm 0.7$ & $1.9 \pm 1.8$ & $2.6 \pm 1.6$ & $2.8 \pm 1.9$ & $2.0 \pm 1.6$ & $1.8 \pm 0.7$ \\
\hline $\begin{array}{l}\text { Systolic BP } \\
\text { (mmHg) }\end{array}$ & $143.5 \pm 28.5$ & $145.5 \pm 38.2$ & $141.1 \pm 26.1$ & $142.6 \pm 19.1$ & $141.3 \pm 28.5$ & $143.8 \pm 23.5$ \\
\hline $\begin{array}{l}\text { Diastolic BP } \\
(\mathrm{mmHg})\end{array}$ & $89.1 \pm 19.2$ & $89.3 \pm 11.9$ & $88.1 \pm 23.1$ & $83.1 \pm 38.9$ & $88.3 \pm 11.9$ & $89.1 \pm 23.8$ \\
\hline $\begin{array}{l}\text { Heart rate } \\
\text { (beats/min) }\end{array}$ & $68.8 \pm 9.8$ & $68.8 \pm 8.9$ & $69.2 \pm 11.1$ & $62.9 \pm 11.2$ & $68.2 \pm 8.9$ & $68.9 \pm 8.2$ \\
\hline
\end{tabular}

Data are shown as mean \pm SD. BMI, body mass index; HDL, High-density lipoprotein; LDL, Low-density lipoprotein; HbA1c, glycohemoglobin A1c; HOMA-IR, insulin resistance by homeostasis model assessment; BP, blood pressure.

\section{Postprandial endothelial dysfunction}

It is known that endothelial dysfunction occurs postprandially and that postprandial hyperglycemic spikes may induce endothelial dysfunction. This phenomenon is probably linked to reduced production and bioavailability of nitric oxide (NO), since hyperglycemia-induced endothelial dysfunction is counterbalanced by arginine [26]. Kawano et al. [11] investigated endothelial function during oral glucose tolerance testing (OGTT) using brachial FMD in 3 groups of subjects with either normal glucose tolerance, impaired glucose tolerance, or type 2 diabetes. At $60 \mathrm{~min}$ after a glucose load, FMD was significantly reduced in all groups. They also found that FMD was inversely correlated with plasma levels of thiobarbituric acid reactive substances as well as plasma glucose levels at $60 \mathrm{~min}$ after a glucose load. Their results suggest that postprandial hyperglycemia rapidly impairs endothelial function through an increase in hyperglycemiainduced oxidative stress.

\section{Cookie load and postprandial hyperglycemia}

In most studies, postprandial endothelial dysfunction has been evaluated using OGTT. However, normal meal ingestion does not involve carbohydrate alone but also includes includes fat and protein. Meal absorption is a complex phenomenon in which postprandial hypertriglyceridemia as well as postprandial hyperglycemia are simultaneously present in the post-absorptive phase, particularly in patients with diabetes. Ceriello et al. have demonstrated that there are independent and cumulative effects of postprandial hypertriglyceridemia and postprandial hyperglycemia on endothelial function and have pointed out that oxidative stress is a common mediator of 


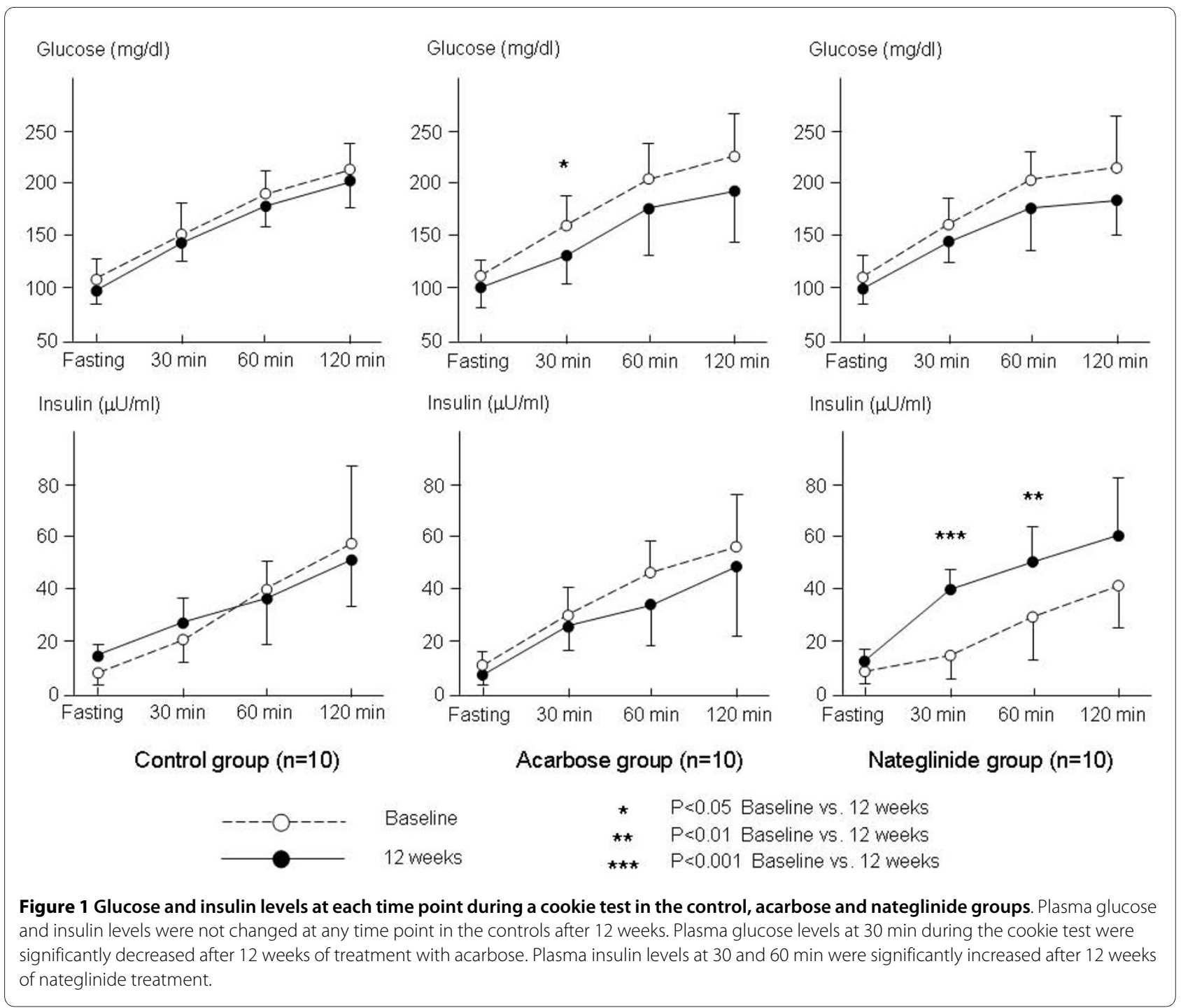

both postprandial states [27]. Harano et al. [22] showed that both hyperglycemia and hypertriglyceridemia occur after a cookie load. Although we did not assess triglyceride levels during the cookie test, postprandial endothelial dysfunction in the present study may in part result from postprandial hypertriglyceridemia in addition to postprandial hyperglycemia.

In our results, the effects of acarbose on improvement of postprandial endothelial dysfunction were superior to those of nateglinide, despite the fact that both agents similarly reduced postprandial plasma glucose levels. Although acarbose and nateglinide are both effective in moderating postprandial hyperglycemia, their mechanisms are quite different. Acarbose acts by competitively inhibiting the $\alpha$-glucosidases, a group of key enzymes involved in the digestion of carbohydrates. Acarbose reduces both postprandial hyperglycemia and hyperinsulinemia, and thereby may improve sensitivity to insulin and alleviate stress on pancreatic $\beta$-cells. In contrast, nateglinide, a glinide compound, selectively enhances early meal-induced insulin secretion and thus improves mealtime glucose control.

In our study, both acarbose and nateglinide similarly inhibited postprandial hyperglycemia as assessed by AUC for glucose levels. While nateglinide increased the AUC for insulin, acarbose did not increase postprandial insulin secretion. Therefore, acarbose may improve postprandial endothelial function by inhibiting postprandial hyperglycemia without increasing postprandial insulin secretion, while nateglinide may improve postprandial endothelial function less significantly by inhibiting postprandial hyperglycemia with an increase in postprandial insulin secretion. Recently, Arcano et al. [28] reported that insulin may cause endothelial dysfunction in humans. Athough the mechanisms through which insulin might impair endothelial function are not well clarified, the 


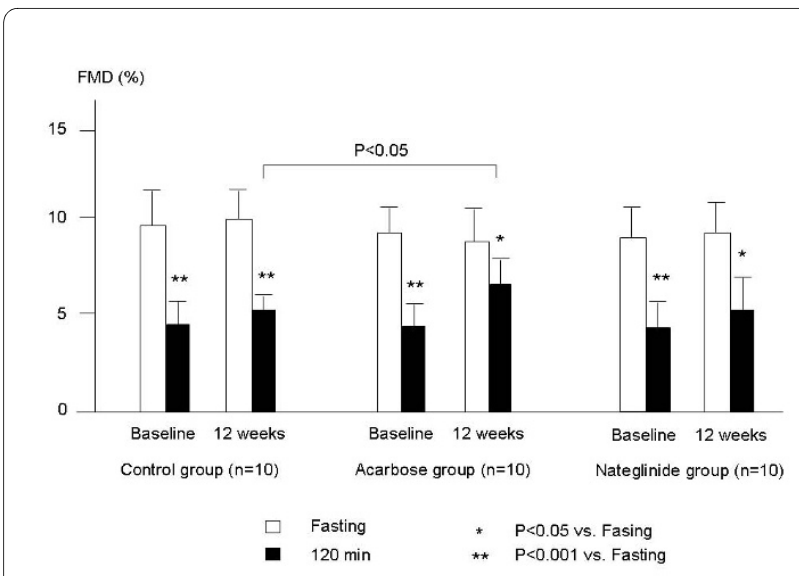

Figure 2 Fasting and postprandial FMD at baseline and 12 weeks after treatment in the control, acarbose and nateglinide groups. At baseline before treatment, fasting FMD was similar among the 3 groups. Postprandial FMD (120 min after cookie load) was significantly lower than fasting FMD in each group. After 12 weeks of treatment, fasting FMD was not significantly different in any of the 3 groups compared to baseline before treatment. Postprandial FMD was lower than fasting FMD in all 3 groups. Postprandial FMD was significantly higher in the acarbose group than in the control group after 12 weeks of treatment.

hyperinsulinemia-induced increase in oxidative stress appears to be involved. Since vitamin C completely reversed insulin-induced endothelial dysfunction without affecting the vascular endothelium-independent response, they speculated that oxidative stress was one of the intermediate steps in insulin-induced endothelial dysfunction. Another recent study showed that insulin activates both the nitrergic and the endothelinergic systems [29]. Endothelin-1 induces $\mathrm{NAD}(\mathrm{P}) \mathrm{H}$ oxidase expression in human endothelial cells, with increased generation of superoxide anions [30]. It is also known that exogenous hyperinsulinemia activates $\mathrm{NAD}(\mathrm{P}) \mathrm{H}$ in the rat aortic endothelium [31]. Thus, insulin may also cause endothelial dysfunction through increased endothelin-1 availability and through downstream effects on $\mathrm{NAD}(\mathrm{P}) \mathrm{H}$ oxidase and superoxide anion production. Our results may provide evidence that both hyperglycemia and hyperinsulinemia cause endothelial dysfunction.

Shimabukuro et al. $[19,20]$ have previously demonstrated that a single administration of acarbose or nateglinide improved postprandial endothelial dysfunction in type 2 diabetes. However, they did not compare the long-term effects of both agents on postprandial endothelial function. A recent study by Major-Pedersen et al. [32] showed that postprandial endothelial dysfunction could be prevented by a single administration of nateglinide, but this effect was abolished after 12 weeks of nateglinide treatment. They speculated that chronically increased insulin secretion resulting from long-term nat-

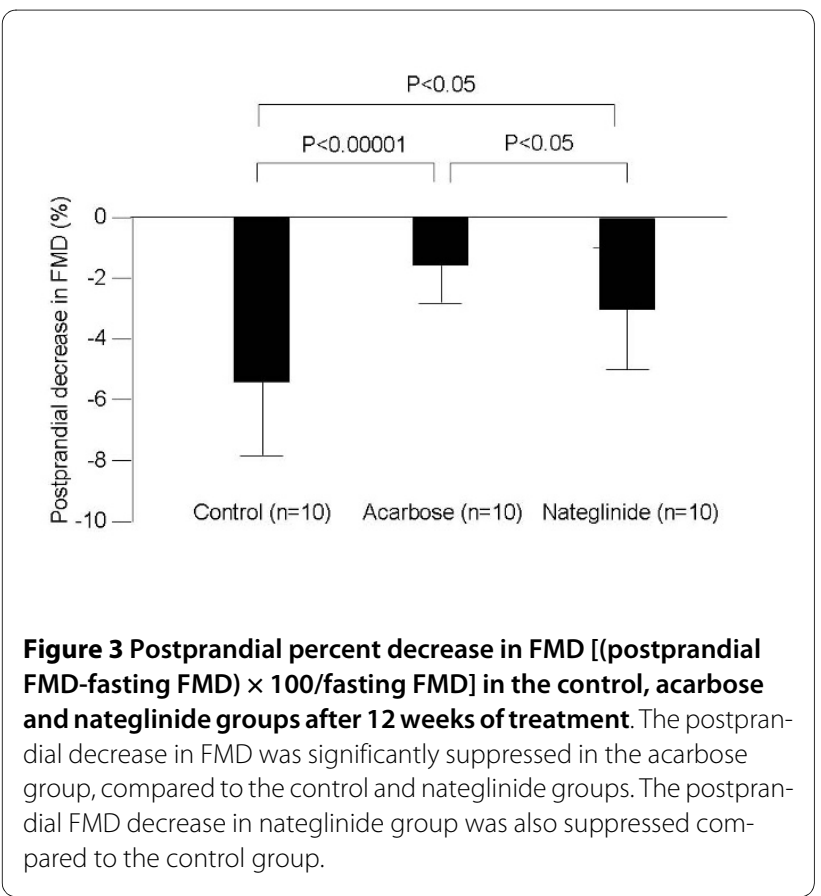

eglinide treatment could counteract the initial beneficial effects of reduced glucose excursion.

\section{Clinical implications/conclusions}

Acarbose improves postprandial endothelial dysfunction in both the short-term (single dose) and in the long-term administration. Our findings appear to partially support the results of the STOP-NIDDM trial [14] and a metaanalysis of several clinical studies [18].

\section{Competing interests}

The authors declare that they have no competing interests.

\section{Authors' contributions}

KN conceived the study; TI drafted the manuscript; TK was involved in the study design, coordination, laboratory measurements and data acquisition; All authors approved the final version of the manuscript.

\section{Author Details}

1Department of Cardiovascular and Renal Medicine, Saga University Faculty of Medicine, Saga, Japan, 2Department of Cardiovascular Medicine, Dokkyo Medical University, Mibu, Tochigi, Japan and 3Department of Cardiovascular and Renal Medicine, Saga University Faculty of Medicine, Saga, Japan

Received: 9 October 2009 Accepted: 24 March 2010

Published: 24 March 2010

\section{References}

1. Tominaga $\mathrm{M}$, Eguchi $\mathrm{H}, \mathrm{Manaka} \mathrm{H}$, et al:: Impaired glucose tolerance is a risk factor for cardiovascular disease, but not impaired fasting glucose. The Funagata Diabetes Study. Diabetes Care 1994, 22:920-924.

2. DECODE Study Group, the European Diabetes Epidemiology Group: Glucose tolerance and cardiovascular mortality: comparison of fasting and 2-hour diagnostic criteria. Arch Intern Med 2001, 161:397-405.

3. Lerman A, Zeiher AM: Endothelial function: cardiac events. Circulation 2005, 111:363-368.

4. Kato T, Inoue T, Morooka T, et al:: Short-term passive smoking causes endothelial dysfunction via oxidative stress in nonsmokers. Can J Physiol Pharmacol 2006, 84:523-529. 
5. Sorensen KE, Celermajer DS, Georgakopoulos D, et al:: Impairment of endothelium-dependent dilation is an early event in children with familial hypercholesterolemia and is related to the lipoprotein (a) level. J Clin Invest 1994, 93:50-55.

6. Lee IK, Kim HS, Bae JH: Endothelial dysfunction: its relationship with acute hyperglycaemia and hyperlipidemia. Int J Clin Pract 2002, 129(suppl):59-64

7. Higashi Y, Nakagawa K, Kimura M, et al.: Circadian variation of blood pressure and endothelial function in patients with essential hypertension:a comparison of dippers and non-dippers. J Am Coll Cardiol 2002, 40:2039-2043.

8. Higashi Y, Sasaki S, Nakagawa K, et al:: Endothelial function and oxidative stress in renovascular hypertension. N Engl J Med 2002, 346:1954-1962.

9. Tack CJ, Ong MK, Lutterman JA, et al.: Insulin-induced vasodilatation and endothelial function in obesity/insulin resistance: effects of troglitazone. Diabetologia 1998, 41:569-576.

10. Tooke JE, Goh KL: Vascular function in type 2 diabetes mellitus and prediabetes: the case for intrinsic endotheiopathy. Diabet Med 1999, 16:710-715

11. Kawano H, Motoyama $T$, Hirashima O, et al.: Hyperglycemia rapidly suppresses flow-mediated endothelium-dependent vasodilation of brachial artery. J Am Coll Cardiol 1999, 34:146-154.

12. Williams SB, Goldfine AB, Timimi FK, et al:: Acute hyperglycemia attenuates endothelium-dependent vasodilation in humans in vivo. Circulation 1998, 97:1695-1701

13. Shige $H$, Ishikawa T, Suzukawa M, et al:: Endothelium-dependent flowmediated vasodilation in the postprandial state in type 2 diabetes mellitus. Am J Cardiol 1999, 84:1272-1274.

14. Hanefeld M, Cagatay M, Petrowitsch T, et al.: Acarbose reduces the risk for myocardial infarction in type 2 diabetic patients: meta-analysis of seven long-term studies. Eur Heart J 2004, 25:10-16.

15. Chiasson JL, Josse RG, Gomis R, et al:: Acarbose treatment and the risk of cardiovascular disease and hypertension in patients with impaired glucose tolerance: the STOP-NIDDM trial. JAMA 2003, 290:486-494.

16. Ai M, Tanaka A, Ogita K, Shimokado K: Favorable effects of early insulin secretion by nateglinide on postprandial hyperlipidemia in patients with type 2 diabetes. Diabetes Care 2006, 29:1180.

17. Mari A, Gastaldelli A, Foley JE, et al:: Beta-cell function in mild type 2 diabetic patients: effects of 6-month glucose lowering with nateglinide. Diabetes Care 2005, 28:1132-1138.

18. Johnston PS, Lebovitz HE, Coniff RF, et al:: Advantages of alphaglucosidase inhibition as monotherapy in elderly type 2 diabetic patients. J Clin Endocrinol Metab 1998, 83:1515-1522.

19. Shimabukuro M, Higa N, Chinen l, et al:: Effects of a single administration of acarbose on postprandial glucose excursion and endothelial dysfunction in type 2 diabetic patients: a randomized crossover study. J Clin Endocrinol Metab 2006, 91:837-842.

20. Shimabukuro M, Higa N, Takasu N, et al: A single dose of nateglinide improves post-challenge glucose metabolism and endothelial dysfunction in Type 2 diabetic patients. Diabet Med 2004, 21:983-986.

21. American Diabetes Association: Diagnosis and classification of diabetes mellitus. Diabetes Care 2004, 27:S5-10.

22. Harano Y, Miyawaki T, Nabiki S, et al:: Development of cookie test for the simultaneous determination of glucose intolerance, hyperinsulinemia, insulin resistance and postprandial dyslipidemia. Endocr J 2006, 53:173-180

23. Matthews DR, Hosker JP, Rudenski AS, et al:: Homeostasis model assessment: insulin resistance and beta-cell function from fasting plasma glucose and insulin concentrations in man. Diabetologia 1985 28:412-419.

24. Friedewald WT, Levy RI, Fredrickson DS: Estimation of the concentration of low-density lipoprotein cholesterol in plasma without use of the ultracentrifuge. Clin Chem 1972, 18:449-502.

25. Corretti MC, Anderson TJ, Benjamin EJ, et al.: Guidelines for the ultrasound assessment of endothelial-dependent flow-mediated vasodilation of the brachial artery: a report of the International Brachial Artery Reactivity Task Force. J Am Coll Cardiol 2002, 39:257-265.

26. Inoue T, Matsuoka $H$, Higashi $Y$, et al:: Flow-mediated vasodilation as a diagnostic modality for vascular failure. Hypertens Res 2008, 31:2105-2113.

27. Ceriello A, Taboga C, Tonutti L, et al:: Evidence for an independent and cumulative effect of postprandial hypertriglyceridemia and hyperglycemia on endothelial dysfunction and oxidative stress generation: effects of short- and long-term simvastatin treatment. Circulation 2002, 106:1211-1218.

28. Arcaro G, Cretti A, Balzano S, et al.: Insulin causes endothelial dysfunction in humans sites and mechanism. Circulation 2002, 105:576-582.

29. Cardillo C, Nambi SS, Kilcoyne CM, et al:: Insulin stimulates both endothelin and nitric oxide activity in the human forearm. Circulation 1999, 100:820-825.

30. Duerrschmidt N, Wippich N, Goettsch W, et al:: Endothelin-1 induces $\mathrm{NAD}(\mathrm{P}) \mathrm{H}$ oxidase in human endothelial cells. Biocham Biophys Res Commun 2000, 269:713-717.

31. Kashiwagi A, Shinozaki K, Nishio Y, et al:: Endothelium-specific activation of $\mathrm{NAD}(\mathrm{P}) \mathrm{H}$ oxidase in aortas of exogenously hyperinsulinemic rats. Am J Physiol 1999, 277:E976-E983.

32. Major-Pedersen A, Ihlemann N, Hermann TS, et al.: Effects of acute and chronic attenuation of postprandial hyperglycemia on postglucose load endothelial function in insulin resistant individuals: is stimulation of first phase insulin secretion beneficial for the endothelial function? Horm Metab Res 2008, 40:607-613.

doi: $10.1186 / 1475-2840-9-12$

Cite this article as: Kato et al., Postprandial endothelial dysfunction in subjects with new-onset type 2 diabetes: an acarbose and nateglinide comparative study Cardiovascular Diabetology 2010, 9:12

\section{Submit your next manuscript to BioMed Central and take full advantage of:}

- Convenient online submission

- Thorough peer review

- No space constraints or color figure charges

- Immediate publication on acceptance

- Inclusion in PubMed, CAS, Scopus and Google Scholar

- Research which is freely available for redistribution
C BioMed Central 